\title{
CORRESPONDENCE
}

\section{Model of Destruction}

SIR,-I agree with the conclusions put forward by Joseph Salerno ${ }^{1}$ in his article on Forrester's world dynamics model, in which he showed that this model was exceedingly sensitive to the input assumptions. Forrester did not, of course, claim that his model was accurate in detail, although he certainly gave the impression in his book that he believed the fundamental finding - that any model would lead to a destructive situation in a finite time.

I believe that there is a much more serious fault in his model as applied to sophisticated populations. He makes the specific statement (page 18 of World Dynamics) "A rate of flow is controlled only by one or more of the system levels and not by other rates" This assumption would be perfectly correct if applied to the interactions of assemblages of molecules, or even of ants or rodents. It is, however, quite untenable when applied to the present world population.

As an example, I would point out that the very considerable fuss, which led to the drastic restriction of the use of DDT in the United States and elsewhere, was due hardly at all to the effects of the actual level of DDT in the environment, but almost entirely to concern about extrapolations of its future effect. These extrapolations obviously depended upon the rate of increase of use of DDT and not merely on its current level, which it is difficult to show to have been responsible for any deaths among the general public, other than those in handling accidents common to, but less than, other pesticides which have not been banned.

Similarly, the rise in exceedingly sensible concern about world population increase, and such actions as liberalization of the laws concerning contraceptives, and so on, are also based on concern about the rates of rise, and extrapolations therefrom, much more than on the absolute levels. In fact, at long last we are crying before we are hurt, or at least before we are hurt much, which is the sensible and effective time to cry.

If one includes in the computer analysis terms which depend upon rates of increase of the factors involved, there seems no reason why a stable model should not be achieved. Whether such a stable state can be attained in practice depends, of course, on whether we act on our concerns rather than whether we express them. I am not prophesying that we shall achieve a viable stable state and I think that Forrester's book can be regarded as a very valuable warning that we must act on his extrapolations if we are to have any hope of avoiding them.

Yours faithfully, J. H. FREMLIN

Department of Physics,

Chancellor's Court,

The University of Birmingham,

PO Box 363,

Birmingham B15 2TT

${ }^{1}$ Salerno, J., Nature, 244, 488 (1973).

\section{Errata}

IN the article "Colour Opponent Neurones in the Human Visual System" by Josef P. J. Rauschecker, Fergus W. Campbell and Janette Atkinson (Nature, 245,$43 ; 1973$ ), line 1 , paragraph 7 , should read "Monocular rivalry thus depends not only on the relative..." not "Binocular rivalry . . .".

IN the article "First Record of the Palaeocene Primate Chiromyoides from North America" by Philip Gingerich (Nature, 244, 517; 1973) two lines were omitted from the last sentence of paragraph 9 which should read "The living Tarsius has primitive lower molars of the Pelycodus-Teilhardina-Tetonoides pattern, but the postprotocingulum is not retained on the upper molars. The remaining living primates have molars derived from the Pelycodus-Teilhardina-Tetonoides pattern, the most primitive modification being the development of a hypocone from the primitive postprotocingulum."

\section{Subscriptions to NATURE}

Subscription Department, Macmillan Journals Ltd., Brunel Road, Basingstoke, Hampshire RG21 2XS.

Please send me 52 issues of NATURE starting with the issue dated $\ldots . . . . . . \ldots .$.

I enclose f16. (USA \& Canada f20.) (Prices applicable only to orders received before 31 st December 1973.)

\section{NAME}

\section{ADDRESS}

\author{
Editorial Department \\ MACMILLAN JOURNALS LIMITED \\ 4 LITTLE ESSEX STREET, LONDON WC2R 3LF \\ Tolephone Number: 01-836 6633. Telegrams: Phusis London WC2R 3LF \\ Telex 262024 \\ MACMILLAN JOURNALS LIMITED \\ 711 NATIONAL PRESS BUILDING \\ WASHINGTON DC 20004 \\ Telephone Number: $202-737$ 2355. Telex 64280 \\ Subscription Department \\ MACMILLAN JOURNALS LIMITED \\ BRUNEL ROAD, BASINGSTOKE, HANTS RG21 2XS \\ Telephone Number: Basingstoke 29242 \\ Display Advertisement Department \\ MACMILLAN JOURNALS LIMITED \\ 4 LITTLE ESSEX STREET, LONDON WC2R 3LF \\ Tolephone Numbers: UK 01-836 6633. USA 202-737 2355 \\ Classified advertisements \\ T G, SCOTT \& SON LIMITED \\ 1 CLEMENT'S INN, LONDON WC2A 2ED \\ Telephone Number: 01-242 6264/01-405 4743 \\ Telegrams: Textualist London WC2A 2ED \\ Registered as a newspaper at the Post Office
}

Copyright (C) Macmillan Journals Limited. September 281973 